Conference Presentation

Practical Characterisation of the Piezo electric Properties of a 3K T300 Carbon Fibre for Impact Sensoring

Mischok, F., Durieux, O., Vagapov, Y., Fedyashin, D.

This is a paper presented at the IEEE Int. Conf. of Russian Young Researchers in

Electrical and Electronic Engineering (EIConRus), Moscow, Russia, 29 Jan - 1 Feb 2018

Copyright of the author(s). Reproduced here with their permission and the permission of the conference organisers.

Recommended citation:

Mischok, F., Durieux, O., Vagapov, Y., Fedyashin, D. (2018) 'Practical Characterisation of the Piezo electric Properties of a 3K T300 Carbon Fibre for Impact Sensoring'. In: Proc. IEEE Int. Conf. of Russian Young Researchers in Electrical and Electronic Engineering (EIConRus), Moscow, Russia, 29 Jan - 1 Feb 2018, pp. 1757-1760. doi: 10.1109/EIConRus.2018.8317446 


\section{Practical Characterisation of the Piezo Electric Properties of a 3K T300 Carbon Fibre for Impact Sensoring}

\author{
Frank Mischok, Olivier Durieux, Yuriy Vagapov \\ School of Applied Science, Computing and Engineering \\ Glyndwr University \\ Plas Coch, Mold Road, Wrexham, LL11 2AW, UK
}

\author{
Dmitriy Fedyashin \\ Department of Computer Science \\ National Research University of Electronic Technology \\ 1 Shokin Square, Zelenograd, Moscow, 124498, Russia
}

\begin{abstract}
This paper discusses the results obtained during the practical characterization of the piezo electric properties of a commonly used carbon fibre. The aim of the investigation was to prepare the grounds for the feasibility of a low cost impact sensor that could be included in any carbon fibre structure (megalithic or thin structure) without interfering the integrity of the actual structure itself. The entire measurement loop as well as the techniques of connectivity of the fibres to the loop is described within. The piezo electric effects and all factors which affect the measurements are reflected in the analysis. The results obtained shown that in normal laboratory conditions the piezo-electric response of a $\mathrm{T300}$ carbon fibre is consistent and directly proportional to the impact applied to the fibre.
\end{abstract}

Keywords-piezo electric effects; carbon fibre structures; low cost impact sensoring

\section{INTRODUCTION}

Nowadays, Carbon Fibre Reinforced Plastics (CFRP) are widely used in various industrial applications. Their advantages over many traditional materials have been demonstrated on many occasions. The manufacturing process of the CFRP has also been extensively investigated, including the cure of the composite using microwave heating [1]. The cure of the composite, particularly the thick elements, is proven to be a challenge during the production. A simple analogy to culinary science will be the cooking of cakes. The outside of any product are rarely warming up at the same pace as the inside: the outside cooks faster than the inside, resulting in a difference of baking pace, leading to structural differences and ultimately cracks on the outer surfaces of the baked cake [2].

The use of the traditional and Microwaves Techniques (MWT) of heating developed by Papaygaris et al. [1] allows uniforming temperatures across the section and a reduction of the internal stresses. Unfortunately, such MWT methods are incompatible with the use of the traditional temperature sensors. Any other sensoring techniques, for stress monitoring (foil strain gauge) in particular, are also being made obsolete because of their reaction under MWT. They may also have a negative structural influence by generating point of stress concentration [3].
Furthermore, the Non Destructive Techniques (NDT) recently developed for measurement of defaults in CFRP are expensive and demanding for field applications.

With this in mind, the need for the development of a low cost, homogenous, stress sensor capable of measuring temperature changes and fast changes of stress (impact) is genuine. In order to do so, extensive study of the electrical characteristics of the commercially used fibres is needed [4].

\section{Methodology}

The methodology used for the evaluation of the electrical response of the fibre has been developed over numerous attempts of characterisation. As it stands, the testbed is made of a fixed aluminium beam on to which numerous elements are attached.

The choice of having a $1 \mathrm{~m}$ long test fibre came as natural. Some evaluations of the response of shorter specimens have been made; the response is proportional to the length of the sensing element since the stress/energy is equally distributed along the sensor. Having a $1 \mathrm{~m}$ long sensor made the quantification of the results easier and allowed to provide the data as "per meter" of sensor length [5].

Many techniques have been tested and benchmarked using modern accelerometers [6]. At first, the repeatability of the mechanical impact has been considered.

Stepper motors were initially preferred to create and control the movement of a fixed mass impactor, this was the best option to modify easily and conveniently the impacting energy. This option had to be aborted due to the negative effect on the stability and veracity of the measurements linked to the Electromagnetic Interferences (EMI) that the motors were generating [7]. The pneumatic option for the actuation of the impactor has been selected because of it relative convenience of use (variation of the speed), it offers a good repeatability (measured systematic error under $0.5 \%$, random under $1 \%$ ).

The measurement loop is very traditional and consists of a Vishay scanner for strains/micro-voltages. The connections between the sensing fibres and the measurements loop have also been evaluated. Many option had to be assessed including 
gold plating of the connection area. Existing silver based epoxies have shown extremely good advantages over gold plating, in particular for field use.

Silver based epoxies are however incompatible with the MWT due to their structures. An innovative compound compatible with all existing curing methods and NDT has been developed using carbon nanotubes (Patent under review).

Fig. 1 below shows the latest test bed capable of creating longitudinal impacts on a fibre.

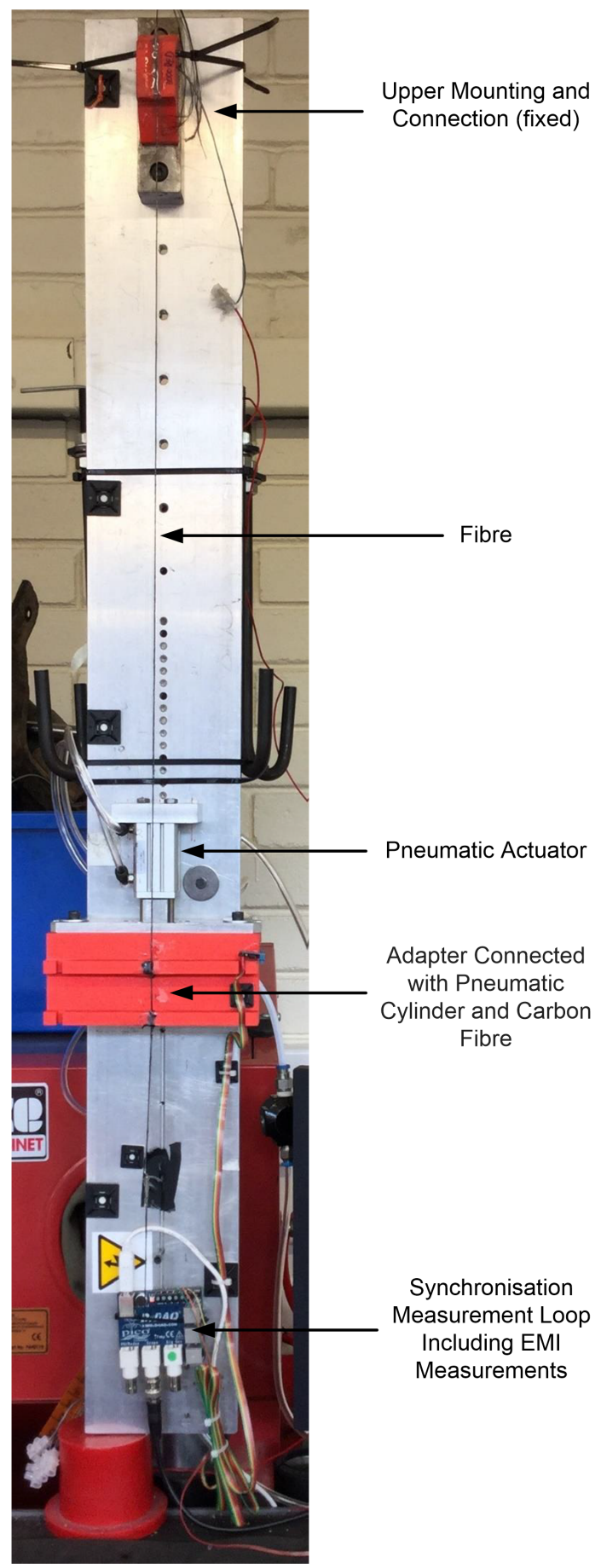

Fig. 1. Test bed

\section{MeAsurement TeChNiQues}

Fig. 2 and 3 shows the results of the preliminary tests done in order to validate and calibrate the measurement technique. $\Delta T_{1}$ is the delay time occurring after the initiation of the impact and the beginning of the response of the carbon fibre. $\Delta T_{2}$ is the time which to reach the maximum amplitude. $T$ is the reaction occurring after initiation to the maximum amplitude of the measurement. $\mathrm{V}$ is the measured value for the difference of electrical potential between the upper and lower mounting areas. $\Delta \mathrm{V}$ is the voltage change of the piezoelectrical effect occurring at two points in time.

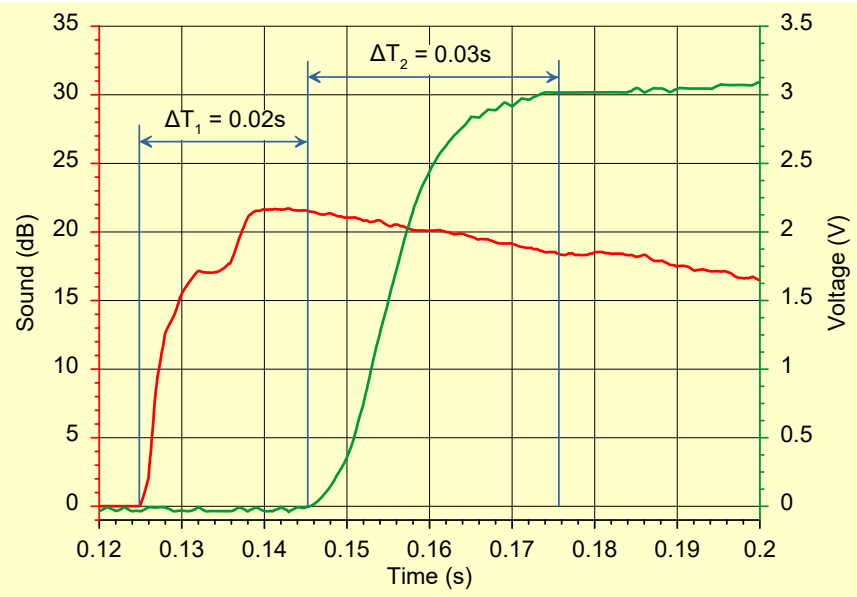

Fig. 2. Standard charge behaviour.

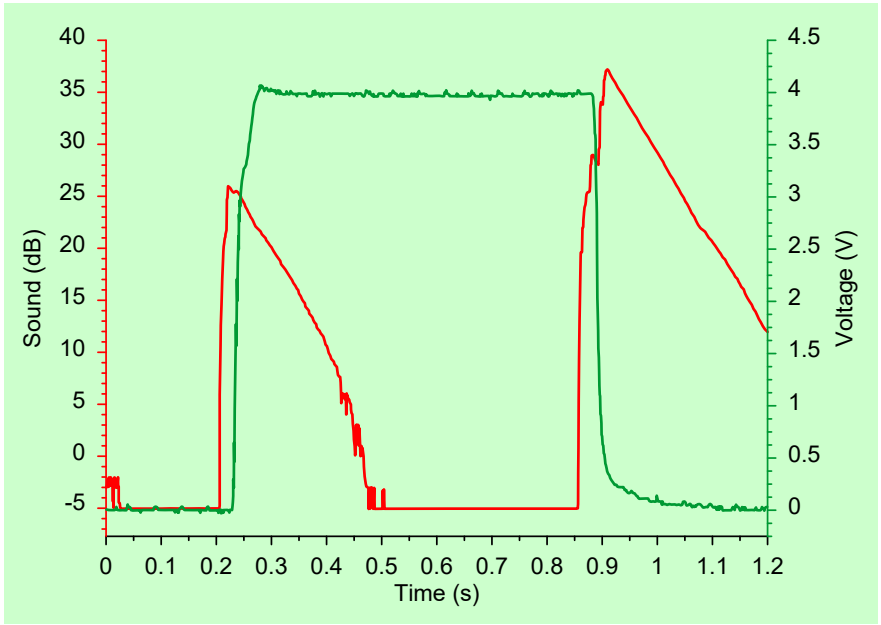

Fig. 3. Response of a $3 \mathrm{~K} \mathrm{~T} 300$ fibre to fast application and release of longitudinal impact of $10 \mathrm{~J}$.

Fig. 3 shows a $3 \mathrm{~K}$ T300 fibre subjected to $10 \mathrm{~J}$ of impact. Two movements are shown, in red is the actuation in the form of a spine. The first movement (at time $0.2 \mathrm{~s}$ ) is a tensional load while the second (at $0.85 \mathrm{~s}$ ) is the release of the stress. The green line depicts the potential change of the carbon fibre and shows an amplitude of approximately $4 \mathrm{~V}$.

\section{OBSERVATION}

Fig. 3 shows interesting phenomenon. The sudden increase of response resulting in an overshoot (zoomed in Fig. 4) of the expected difference of potential is the characteristic of the 
piezo-electric response of the material in this specific load scenario.

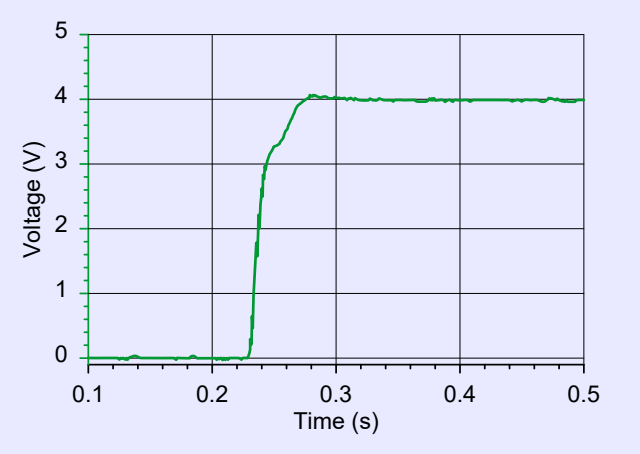

Fig. 4. Detail of Fig 3 showing the observed overshooting of the potential difference

The effect was amplified by the data acquisition loop. The amplification and attached filtration allow the removal of the unwanted EMI. [7] The power gain calculated using voltage instead of power using the Joule's law is:

$$
\operatorname{Gain}(\mathrm{dB})=10 \log \frac{V_{\text {out }}^{2} R_{\text {in }}}{V_{\text {in }}^{2} R_{\text {out }}}
$$

The gain used for the measurement was equivalent to a $10^{3}$ factor. The filtration of the EMC was realised using a combination of low-pass and high pass filtration.

The Table I below shows the actual measurements obtained from a series of 7 tests. No measurements over $\pm 5 \%$ from the median value have been measured in normal conditions.

TABLE I. MEAN COLlECTED DATA AND WORKED OUT VALUES FOR $10 \mathrm{~J}$

\begin{tabular}{|l|l|l|l|}
\hline Time (ms) & Loop Output (V) & Differential (V) & Unamplified value (V) \\
\hline 15 & 1.354 & & \\
\hline 31 & 4.067 & 0.094 & 0.094 \\
\hline 47 & 4.123 & 0.15 & 0.15 \\
\hline 62 & 4.098 & 0.125 & 0.125 \\
\hline 78 & 4.058 & 0.085 & 0.085 \\
\hline 93 & 4.032 & 0.059 & 0.059 \\
\hline 109 & 3.994 & 0.021 & 0.021 \\
\hline 125 & 3.976 & 0.003 & 0.003 \\
\hline
\end{tabular}

At $T=0$, the loop output (pure output of the measurement loop) is $0 \mathrm{~V}$. The impact time is $109 \mathrm{~ms}$ in duration on average. This is the measured time for the release of the $10 \mathrm{~J}$ through the fibre. The differential voltage announced in Table I is calculated using the following equation:

$$
\operatorname{Diff} . \operatorname{Out}(T)=\operatorname{LoopOut}(T)-\overline{\operatorname{LoopOut}(\operatorname{after} T=0.125 \mathrm{~s})}
$$

The unamplified output is calculated by inversing the power gain equation announced above. The application of Ohm's laws for conductor gives:

$$
P=\frac{V^{2}}{R}
$$

where $P$ is the power measured, $V$ is the voltage measured and $R$ is the resistance of the measured conductor (here 120 ).

The equivalent Energy developed by the piezo conductor can be evaluated using the Power (evaluated from the differential output at anytime over the duration of the impact) [8]. Since the differential output is varying over the duration of the impact, the simplest way of determination of the power over the impact is therefore:

$$
E_{\text {piezo }}=\int_{t=0}^{\text {end of impact }} P d t=\int_{t=0}^{\text {end of impact }} \frac{V^{2}}{R} d t
$$

In reality, the summation of the various $\left(V^{2} / R\right)$ can simplified in:

$$
E_{\text {piezo }}=\sum \frac{V^{2}}{R}\left(t_{n+1}-t_{n}\right)
$$

where $t_{n}$ are the time at which every measurement was made.

The value obtained for $E_{\text {piezo }}$ for an impact of $10 \mathrm{~J}$ is $6.41 \mathrm{~W} \cdot \mathrm{s}$. The value of the impact was $10 \mathrm{~J}(10 \mathrm{~W} \cdot \mathrm{s})$, is it therefore acceptable to announce that around $65 \%$ of the mechanical energy that the sensor has been subjected to has been transformed into electrical energy and measured as such.

Similar experimentations have been conducted for 5 and $20 \mathrm{~J}$ impact. Tables II and III show the results obtained for those impacts respectively. Using the same analytical analysis, the value obtained for $E_{\text {piezo }}$ for an impact of $5 \mathrm{~J}$ is $3.16 \mathrm{~W} \cdot \mathrm{s}$.

TABLE II. MEAN COLLECTED DATA AND WORKED OUT VALUES FOR $5 \mathrm{~J}$

\begin{tabular}{|l|l|l|l|}
\hline Time (ms) & Loop output $(\mathbf{V})$ & Differential (V) & Unamplified value (V) \\
\hline 15 & 0.689 & & \\
\hline 31 & 2.098 & 0.032 & 0.032 \\
\hline 47 & 2.151 & 0.085 & 0.085 \\
\hline 62 & 2.134 & 0.068 & 0.068 \\
\hline 78 & 2.122 & 0.056 & 0.056 \\
\hline 93 & 2.092 & 0.026 & 0.026 \\
\hline 109 & 2.078 & 0.012 & 0.012 \\
\hline 125 & 2.067 & 0.001 & 0.001 \\
\hline
\end{tabular}

TABLE III. MEAN COLLECTED DATA AND WORKED OUT VALUES FOR $20 \mathrm{~J}$

\begin{tabular}{|l|l|l|l|}
\hline Time (ms) & Loop output (V) & Differential (V) & Unamplified value (V) \\
\hline 15 & 2.71 & & \\
\hline 31 & 8.14 & 0.183 & 0.183 \\
\hline 47 & 8.255 & 0.293 & 0.293 \\
\hline 62 & 8.21 & 0.247 & 0.247 \\
\hline 78 & 8.121 & 0.157 & 0.157 \\
\hline 93 & 8.068 & 0.105 & 0.105 \\
\hline 109 & 7.994 & 0.031 & 0.031 \\
\hline 125 & 7.964 & 0.002 & 0.002 \\
\hline
\end{tabular}


$E_{\text {piezo }}$ calculated from the above data, for an impact of $20 \mathrm{~J}$, is $13.83 \mathrm{~W} \cdot \mathrm{s}$. Table IV shows the different values of harvested energy for various longitudinal impacts as well as the response of the system in $\mathrm{W} \cdot \mathrm{s} / \mathrm{J}$ (calculated using the mean values of the measurements).

TABLE IV. REVIEW OF THE RESPONSE

\begin{tabular}{|c|c|c|c|}
\hline Impact Developed $(\mathrm{J})$ & 5 & 10 & 20 \\
\hline Energy harvested $(\mathrm{W} \cdot \mathrm{s})$ & 3.16 & 6.41 & 13.83 \\
\hline Response $(\mathrm{W} \cdot \mathrm{s} / \mathrm{J})$ & $63.2 \%$ & $64.1 \%$ & $69.2 \%$ \\
\hline
\end{tabular}

Between 5 and $20 \mathrm{~J}$, a relative consistency in the ratio Energy measured/impact is noted. The current settings are refraining the production of accurate impacts over $25 \mathrm{~J}$ so it is, in the current state of play, impossible to conclude any further in the linearity of the response of the fibre to impact. It is, however, possible to note that the response of the fibre is, as predicted, linear between 0 and $20 \mathrm{~J}$.

\section{CONCLUSIONS}

This investigation observes that, in normal laboratory conditions (at a constant temperature of $20^{\circ} \mathrm{C}$ and a normal degree of hygrometry) the piezo-electric response of a T300 carbon fibre is consistent and directly proportional to the impact applied to the fibre. The measurement of the piezoelectric response was realised using traditional strain equipment and evaluated by focusing on the overshoot of the response of the conductor. The stain gauge effects of the carbon fibres (in particular the gauge factor) have voluntarily been neglected from this analysis, as they do not offer any novelty in their study, the overshoot in the response is the only point of focus in the evaluation of the piezo-electric effect. The investigation has shown that the amount of overshoot (area of the measured response - stabilised response) is proportional to the speed at which the stress is applied (impact). It is therefore possible to conclude that the fibre can be used as a strain as well as an impact sensor for further development.

\section{REFERENCES}

[1] D.A. Papargyris, R.J. Day, A. Nesbitt, and D. Bakavos, "Comparison of the mechanical and physical properties of a carbon fibre epoxy composite manufactured by resin transfer moulding using conventional and microwave heating," Composites Science and Technology, vol. 68, no. 708, pp. 1854-1861, June 2008.

[2] P. Morgon, Carbon Fibers and Their Composites, CRC Press: Boca Raton, 2005.

[3] K. Ladfi, Handbook of Composites, Chapman and Hall: London, 1974.

[4] A. Ledoux, "Theory of piezoelectric materials and their applications," M.Eng. thesis, Dept. Civil and Envir. Eng., MIT, Cambridge, MA, USA, 2011.

[5] S.-J. Park, Classification of Carbon Fibre, Heidelberg: Springer Verlag, 2014.

[6] S. Brage, N. Brage, N. Wedderkopp, and K. Froberg, "Reliability and validity of the computer science and applications accelerometer in a mechanical setting," Measurement in Physical Education and Exercise Science, vol. 7, no. 2, pp. 101-119, 2003.

[7] R.L.Ozenbaugh, and T.M. Pullen, EMI Filter Design, CRC Press: Boca Raton, 2016.

[8] T. Ikeda, Fundamentals of Piezoelectricity, Oxford University Press: Oxford, 1996. 